\title{
Effect of thoracentesis on pulmonary gas exchange
}

\author{
MIGUEL PERPIÑÁ, EDUARDO BENLLOCH, VICENTE MARCO, \\ FRANCISCO ABAD, DOLORES NAUFFAL
}

From the Ciudad Sanitaria “La Fe," Servicio de Neumología, Valencia, Spain

\begin{abstract}
The effect of thoracentesis on pulmonary gas exchange was studied in 33 patients with unilateral pleural effusions of various causes. Arterial blood gases were measured before thoracentesis and at 20 minutes, two hours, and 24 hours after the procedure. In 13 patients alveolar arterial oxygen gradient $\left(\mathrm{P}_{\mathrm{A}}-\mathrm{ao}\right)$, physiological dead space:tidal volume ratio (VD/VT), physiological shunt, and "anatomical" shunt were also determined before and two hours after thoracentesis. The Pao, showed a significant increase at each time, reaching a maximum at 24 hours (mean (SD) increase $1 \cdot 1(0 \cdot 74) \mathrm{kPa} ; 8 \cdot 17(5.57) \mathrm{mm} \mathrm{Hg})$. A concurrent significant decrease of $\mathrm{PA}_{\mathrm{A}}$ ao was observed (mean (SD) $1.72(0.77) \mathrm{kPa} ; 12.92(5.78) \mathrm{mm} \mathrm{Hg}$ ). This was accompanied by a small but significant decrease of "anatomical" shunt $(2.4 \%(1.5 \%))$ and a greater decrease of the physiological shunt $(6.5 \%(4.3 \%))$, while VD/VT did not change. The results are probably due to improved ventilation perfusion relationships with, in particular, an increase in the ventilation of parts of the lung previously poorly ventilated but well perfused.
\end{abstract}

The effect of thoracentesis on arterial blood oxygenation is controversial; most studies report a decrease in arterial oxygen tension $\left(\mathrm{PaO}_{2}\right)^{1-3}$ and this has been attributed to alteration of ventilation perfusion $\left(\dot{\mathrm{V}}_{\mathrm{A}} /\right.$ Q) matching. Two of these studies, however, were limited to measuring the changes in $\mathrm{Pao}_{2}$ and only Brown et al made measurements of the alveolararterial oxygen tension difference $\left(\mathrm{P}_{\mathrm{A}}-\mathrm{ao}\right)$ and of the "anatomical" shunt fraction. The changed $\dot{V}_{A} / \dot{Q}$ relationships have been attributed to interstitial oedema occurring when blood flow increases abruptly through previously compressed lung, and to negative pressure in the capillary bed produced by decompression. ${ }^{1 \cdot 3+}$

In our experience, decrease of $\mathrm{Pao}$, is not a frequent finding and improvement of the $\mathrm{Pao}$ is the rule. We have studied changes in the arterial blood gases immediately after thoracentesis and two and 24 hours later. We have investigated the possible causes of observed changes by measuring the $\mathrm{PA}_{\mathrm{a}} \mathrm{ao}$, physiological shunt, "anatomical" shunt, and the physiological dead space to tidal volume ratio ( $\mathrm{VD} /$ $\mathrm{VT}$ ).

Address for reprint requests: Dr M Perpiná, Ciudad Sanitaria "La Fe." Servicio de Neumologia, Departmento de Medicina Interna, Avenida de Campana 21, Valencia 9, Spain.

Accepted 6 June 1983

\section{Methods}

We studied 33 patients ( 21 men and 12 women, mean age 55 years, range 25-75) with unilateral pleural effusions of varied causes. The underlying diseases were: cardiac failure ( 7 cases), tuberculous pleurisy (7), bacterial pneumonia (6), bronchogenic carcinoma (5), breast cancer (5), metastatic gastric carcinoma (2), and mesothelioma (1). The mean volume of fluid removed was 1297 (SD 495) ml. Except for the seven cases due to cardiac failure, the effusions were exudates according to the criteria of Light et al. ${ }^{5}$ All patients experienced dyspnoea of varying intensity. Thoracenteses were performed for therapeutic as well as diagnostic purposes. Informed consent was obtained in all cases.

An arterial blood sample was drawn for measurement of $\mathrm{Po}_{2}, \mathrm{Pco}_{2}$, and $\mathrm{pH}$ before thoracentesis in all patients and after the procedure at 20 minutes (16 patients), two hours (25 patients), and 24 hours (12 patients). In 13 of the patients studied at two hours the $\mathrm{PA}_{\mathrm{A}}-\mathrm{aO}_{2}$ and the $\mathrm{VD}_{\mathrm{D}} / \mathrm{VT}_{\mathrm{T}}$ were also determined, as well as the "physiological" shunt and the "anatomical" shunt (see below). In four patients these measurements were repeated at 24 hours.

PLEURAL DRAINAGE

Thoracentesis was performed in the sitting position after local infiltration with lignocaine, by means of an 
18 gauge needle with an internal diameter of $1.2 \mathrm{~mm}$, connected to a standard suction machine with variable suction pressure (Ordisi A-70). After pleural fluid had been obtained for microbiological, chemical, and cytological examination drainage was continued at a rate of about $50 \mathrm{ml}$ a minute. Drainage was terminated when no more fluid could be obtained or when the patient showed discomfort. Within six hours of thoracentesis, a chest radiograph was taken to exclude complications such as pneumothorax or pulmonary oedema.

\section{LABORATORY DETERMINATIONS}

The hospital is at sea level and all the patients were breathing room air throughout the procedure. After local infiltration with lignocaine the blood samples were obtained anaerobically from a radial artery while the patient remained seated. The samples were analysed in duplicate within 10 minutes by an IL 213227 blood gas analyser.

For measurement of the $\mathrm{PA}_{\mathrm{A}}-\mathrm{ao}$, and the $\mathrm{VD} / \mathrm{VT}$ the patients, wearing a nose clip, breathed room air quietly through a one way valve (Hans Rudolph, dead space $15 \mathrm{ml}$ ) into a latex bag of $120 \mathrm{l}$ capacity. After the bag had been flushed three times with the patient's expired gas, the gas was collected for five minutes and the volume measured by emptying the bag into a Tissot spirometer. The concentrations of oxygen and carbon dioxide of the expired gas were determined with Beckman OM-11 and LB-2 analysers respectively, from which the respiratory exchange ratio was calculated. The arterial blood sample was obtained during the last minute of gas collection over at least six respiratory cycles. The $\mathrm{PA}_{\mathrm{A}} \mathrm{aO}_{2}$ was calculated with the alveolar air equation and the VD/VT with the Bohr equation. The physiological shunt was determined by estimating the end pulmonary capillary oxygen content from the calculated $\mathrm{PAO}_{2}$ and the haemoglobin concentration and assuming an arterial venous oxygen content difference of 5 volumes \%. The "anatomical" shunt was measured after the patient had breathed $100 \%$ oxygen for 20 minutes.

The physiological indices were compared with

Table 1 Arterial blood gas tensions and alveolar arterial oxygen tension difference ( $\mathrm{mm} \mathrm{Hg}$ ) before and after thoracentesis at different intervals

\begin{tabular}{|c|c|c|c|c|c|c|c|c|c|c|c|c|}
\hline \multirow{2}{*}{$\begin{array}{l}\text { Patient } \\
\text { No }\end{array}$} & \multicolumn{3}{|c|}{ Baseline } & \multicolumn{3}{|c|}{20 min after thoracentesis } & \multicolumn{3}{|c|}{$2 h$ after thoracentesis } & \multicolumn{3}{|c|}{$24 \mathrm{~h}$ after thoracentesis } \\
\hline & $\mathrm{PaO}_{2}$ & $\mathrm{PaCO}_{2}$ & $P_{A}-a_{2}$ & $\mathrm{PaO}_{2}$ & $\mathrm{PaCO}_{2}$ & $P_{A}-a_{2}$ & $\mathrm{PaO}_{2}$ & $\mathrm{PaCO}_{2}$ & $P_{A}-a_{2}$ & $\mathrm{PaO}_{2}$ & $\mathrm{PaCO}_{2}$ & $P_{A}-a O_{2}$ \\
\hline 1 & 52 & 26 & 65 & 54 & 27 & 62 & 65 & 36 & 40 & 75 & 30 & 37 \\
\hline 2 & 74 & 24 & 46 & 84 & 30 & 28 & 81 & 31 & 30 & 80 & 32 & 30 \\
\hline 3 & 79 & 26 & 38 & 80 & 28 & 35 & 83 & 35 & 23 & 84 & 35 & 22 \\
\hline 4 & 73 & 40 & 59 & 85 & 28 & 30 & 70 & 30 & 42 & 76 & 30 & 36 \\
\hline 5 & 81 & 26 & 36 & 86 & 25 & 33 & 94 & 26 & 33 & 92 & 30 & 20 \\
\hline 6 & 75 & 24 & 45 & 76 & 26 & 41 & 79 & 26 & 38 & 82 & 25 & 37 \\
\hline 7 & 71 & 33 & 38 & 83 & 30 & 29 & 80 & 32 & 30 & 84 & 30 & 28 \\
\hline 8 & 63 & 26 & 54 & 65 & 25 & 53 & 68 & 24 & 52 & 70 & 26 & 47 \\
\hline 9 & 64 & 37 & 40 & 73 & 37 & 31 & & & & & & \\
\hline 10 & 73 & 35 & 33 & 79 & 33 & 30 & & & & & & \\
\hline 11 & 47 & 45 & 47 & 50 & 46 & 42 & & & & & & \\
\hline 12 & 57 & 36 & 48 & 66 & 41 & 33 & & & & & & \\
\hline 13 & 60 & 67 & 6 & 69 & 60 & 6 & & & & & & \\
\hline 14 & 54 & 32 & 56 & 51 & 31 & 60 & & & & & & \\
\hline 15 & 71 & 28 & 44 & 88 & 31 & 23 & & & & & & \\
\hline 16 & 68 & 31 & 43 & 74 & 37 & 30 & & & & & & \\
\hline 17 & 54 & 40 & 46 & & & & 64 & 35 & 42 & & & \\
\hline 18 & 80 & 32 & 30 & & & & 86 & 32 & 24 & & & \\
\hline 19 & 76 & 34 & 31 & & & & 85 & 32 & 25 & & & \\
\hline 20 & 59 & 35 & 47 & & & & 67 & 32 & 43 & & & \\
\hline 21 & 64 & 38 & 43 & & & & 64 & 38 & 38 & 67 & 41 & 32 \\
\hline 22 & 54 & 36 & 50 & & & & 63 & 35 & 45 & 63 & 35 & 47 \\
\hline 23 & 71 & 38 & 36 & & & & 74 & 42 & 30 & 78 & 43 & 18 \\
\hline 24 & 69 & 29 & 54 & & & & 69 & 30 & 45 & 74 & 31 & 43 \\
\hline 25 & 71 & 34 & 36 & & & & 73 & 29 & 41 & & & \\
\hline 26 & 65 & 38 & 37 & & & & 71 & 35 & 35 & & & \\
\hline 27 & 59 & 38 & 44 & & & & 60 & 44 & 35 & & & \\
\hline 28 & 62 & 22 & 65 & & & & 66 & 31 & 45 & & & \\
\hline 29 & 70 & 37 & 41 & & & & 77 & 33 & 38 & & & \\
\hline 30 & 68 & 20 & 57 & & & & 71 & 25 & 48 & & & \\
\hline 31 & 60 & 34 & 47 & & & & 68 & 33 & 41 & & & \\
\hline 32 & 61 & 40 & 39 & & & & 71 & 35 & 35 & & & \\
\hline 33 & 68 & 39 & 33 & & & & 72 & 37 & 32 & & & \\
\hline Mean & $65 \cdot 8$ & 33.9 & 43.4 & $72 \cdot 7$ & 33.4 & 35.4 & $72 \cdot 8$ & $32 \cdot 7$ & $37 \cdot 2$ & $77 \cdot 1$ & $32 \cdot 3$ & $33 \cdot 1$ \\
\hline SD & $8 \cdot 6$ & 8.4 & $11 \cdot 3$ & $12 \cdot 5$ & $9 \cdot 2$ & 13.9 & $8 \cdot 3$ & $4 \cdot 8$ & $7 \cdot \overline{5}$ & $8 \cdot 1$ & $5 \cdot 4$ & 9.9 \\
\hline $\mathrm{p}$ & & & & $<0.001$ & NS & $<0.005$ & $<0.001$ & NS & $<0.001$ & $<0.001$ & NS & $<0.001$ \\
\hline
\end{tabular}

Pao,-arterial oxygen tension: Paco,_arterial carbon dioxide tension: $\mathrm{PA}_{\mathrm{A}}$ ao, - alveolar arterial Po, difference: $\mathrm{NS}$ - not significant. Conversion: Traditional to SI units-Blood gases: $1 \mathrm{kPa}=7.5 \mathrm{~mm} \mathrm{Hg}$. 
baseline values with the paired $t$ test; $\mathrm{p}$ values less than 0.05 were considered significant. The results are expressed as means with standard deviations in parentheses.

\section{Results}

There was an improvement of dyspnoea in all patients after thoracentesis and no complications occurred.

The effect of thoracentesis on the $\mathrm{Pao}_{2}$ is shown in table 1. At 20 minutes $\mathrm{Pao}$, increased in all except patient 14 , in whom a decrease of $0.4 \mathrm{kPa}$ or $3 \mathrm{~mm} \mathrm{Hg}$ was observed; the mean increase was $0.84(0.69) \mathrm{kPa}$ or $6.31(5.21) \mathrm{mm} \mathrm{Hg}$. After two hours the Pao, was higher than before aspiration in 22 patients, had not changed in two, and was lower in one: the mean increase was $0.75(0.54) \mathrm{kPa}$ or $5.68(4.05) \mathrm{mm} \mathrm{Hg}$. Finally, at 24 hours the $\mathrm{PaO}$, was improved in all patients studied, with a mean increase over baseline values of $1.1(0.74) \mathrm{kPa}$ or $8.17(5.57) \mathrm{mm} \mathrm{Hg}$. All these changes in $\mathrm{PaO}_{2}$ were significant $(\mathrm{p}<0.001)$ but no significant changes were found in either $\mathrm{PaCO}_{2}$ or $\mathrm{pH}$ (table 1).

The $\mathrm{PA}_{\mathrm{A}}-\mathrm{aO}_{2}$ decreased at all intervals in all patients except two, in whom it had increased by 0.53 $\mathrm{kPa}$ or $4 \mathrm{~mm} \mathrm{Hg}$ at 20 minutes, and by $0.66 \mathrm{kPa}$ or 5 $\mathrm{mm} \mathrm{Hg}$ at two hours respectively; mean decreases were: at 20 minutes $1 \cdot 10(1 \cdot 17) \mathrm{kPa}$ or $8.29(8.84) \mathrm{mm}$ $\mathrm{Hg}$; at two hours $1.15(0.87) \mathrm{kPa}$ or $8.64(6.55) \mathrm{mm}$ $\mathrm{Hg}$; and at 24 hours $1.72(0.77) \mathrm{kPa}$ or $12.92(5.78)$ $\mathrm{mm} \mathrm{Hg}$. These values were significantly lower than baseline values (table 1 ).

When measurements were made two hours after drainage there was a decrease of the physiological shunt in all patients except one, in whom it remained unchanged (table 2). The mean decrease was $6.5 \%$ $(4.3 \%)(p<0.001)$. The "anatomical" shunt also decreased significantly in these same patients but to a lesser extent $(2.4 \%,(1.5 \%) ; \mathrm{p}<0.001)$. The VD/VT showed a minimal decrease in nine patients and a slight increase in three, and did not change in one; but there was no significant change in the mean value (table 2). In the four patients in whom shunt and $\mathrm{VD} /$ VT were also determined at 24 hours the values were not consistently different from those obtained at two hours (table 2).

The narrow range of volumes of pleural fluid removed in most patients did not permit us to examine any correlation between the amount of fluid extracted and changes in the functional indices measured.

\section{Discussion}

Although the increase of $\mathrm{PaO}_{2}$ observed after thoracentesis was generally modest, it occurred in all except one patient. The increase was evident immediately after the procedure, persisted two hours later, and was even greater at 24 hours. There was a corresponding decrease of the $\mathrm{PA}_{\mathrm{A}}-\mathrm{ao}_{2}$, while the $\mathrm{Paco}$, showed no consistent changes; so the increase in $\mathrm{PaO}_{2}$ cannot be attributed to hyperventilation. Possibly an effusion has different effects on the distribution of ventilation and of perfusion. After thoracentesis some previously collapsed non-ventilated but perfused alveoli may open, thus reducing the "anatomical" shunt, as was observed in our patients. The matching of ventilation to perfusion might also be improved by the decompression of previously constricted capillaries supplying ventilated alveoli. In this study, however, the latter effect

Table 2 Physiological shunt, "anatomical" shunt, and dead space to tidal volume ratio (VD/VT) before and after thoracentesis

\begin{tabular}{|c|c|c|c|c|c|c|c|c|c|}
\hline \multirow{2}{*}{$\begin{array}{l}\text { Patient } \\
\text { No }\end{array}$} & \multicolumn{3}{|l|}{ Baseline } & \multicolumn{3}{|c|}{$2 h$ after thoracentesis } & \multicolumn{3}{|c|}{$24 \mathrm{~h}$ after thoracentesis } \\
\hline & $\begin{array}{l}\text { Physiological } \\
\text { shunt (\%) }\end{array}$ & $\begin{array}{l}\text { "Anatomical" } \\
\text { shunt }(\%)\end{array}$ & $\begin{array}{l}V_{D} / V_{T} \\
(\%)\end{array}$ & $\begin{array}{l}\text { Physiological } \\
\text { shunt (\%) }\end{array}$ & $\begin{array}{l}\text { "Anatomical" } \\
\text { shunt (\%) }\end{array}$ & $\begin{array}{l}V_{D} / V_{T} \\
(\%)\end{array}$ & $\begin{array}{l}\text { Physiological } \\
\text { shunt (\%) }\end{array}$ & $\begin{array}{l}\text { "Anatomical" } \\
\text { shunt }(\%)\end{array}$ & $\begin{array}{l}V_{D} / V_{T} \\
(\%)\end{array}$ \\
\hline $\begin{array}{l}21 \\
22 \\
23 \\
24 \\
25 \\
26 \\
27 \\
28 \\
29 \\
30 \\
31 \\
32 \\
33\end{array}$ & $\begin{array}{l}27 \\
28 \\
29 \\
17 \\
17 \\
24 \\
28 \\
17 \\
16 \\
28 \\
17 \\
19 \\
18\end{array}$ & $\begin{array}{l}16 \\
17 \\
14 \\
10 \\
15 \\
17 \\
17 \\
15 \\
10 \\
16 \\
15 \\
15 \\
13\end{array}$ & $\begin{array}{l}43 \\
47 \\
35 \\
38 \\
46 \\
52 \\
59 \\
32 \\
55 \\
31 \\
52 \\
55 \\
36\end{array}$ & $\begin{array}{l}18 \\
16 \\
17 \\
17 \\
15 \\
16 \\
17 \\
14 \\
10 \\
16 \\
14 \\
16 \\
14\end{array}$ & $\begin{array}{r}14 \\
14 \\
12 \\
10 \\
11 \\
11 \\
15 \\
12 \\
8 \\
12 \\
13 \\
14 \\
12\end{array}$ & $\begin{array}{l}51 \\
45 \\
30 \\
38 \\
41 \\
45 \\
58 \\
38 \\
50 \\
37 \\
50 \\
45 \\
33\end{array}$ & $\begin{array}{l}18 \\
11 \\
14 \\
16\end{array}$ & $\begin{array}{l}14 \\
10 \\
12 \\
10\end{array}$ & $\begin{array}{l}41 \\
41 \\
27 \\
41\end{array}$ \\
\hline $\begin{array}{l}\text { Mean } \\
\text { SD } \\
\text { p }\end{array}$ & $\begin{array}{r}21 \cdot 9 \\
5 \cdot 3\end{array}$ & $\begin{array}{r}14 \cdot 6 \\
2 \cdot 3\end{array}$ & $\begin{array}{r}44 \cdot 7 \\
9 \cdot 5\end{array}$ & $\begin{array}{c}15 \cdot 4 \\
2 \cdot 1 \\
<0 \cdot 001\end{array}$ & $\begin{array}{c}12.1 \\
1.9 \\
<0.001\end{array}$ & $\begin{array}{c}43 \cdot 1 \\
7 \cdot 9 \\
\text { NS }\end{array}$ & $\begin{array}{r}14 \cdot 7 \\
2 \cdot 9\end{array}$ & $\begin{array}{r}11 \cdot 5 \\
1.9\end{array}$ & $\begin{array}{r}37 \cdot 5 \\
5 \cdot 7\end{array}$ \\
\hline
\end{tabular}

NS—not significant. 
could have been only trivial since there were no significant changes in $V_{D} / V_{T}$. On the other hand, some underventilated alveoli with a normal or even increased blood supply might increase their ventilation after thoracentesis, thus improving their matching of ventilation and perfusion and hence the oxygenation of blood leaving these alveoli. This appears to have been the most important mechanism in our patients. The difference observed between the physiological and "anatomical" shunts is attributable to improvement of ventilation perfusion mismatching. A further factor may be an increase of the diffusing capacity of the lung, mainly due to an increase of the available area for gas exchange; but the diffusing capacity did not show any changes in the study reported by Light $e$ t al. ${ }^{6}$

Our results do not agree with those of some other studies. Karetzky et al ${ }^{1}$ studied 17 patients and concluded that the change in $\mathrm{Pao}$ one hour after thoracentesis was unpredictable. Brandstetter and Cohen $^{3}$ in a series of 15 cases found an initial systematic decrease of the $\mathrm{PaO}_{2}$, which had returned to preaspiration values by 24 hours. They attributed these changes to altered capillary permeability, due to a sudden increase of blood flow in the previously collapsed lung or ventilation perfusion abnormalities, or both. On the other hand, Brown et al observed an increase of $\mathrm{PaO}_{2}$ in five of six patients studied three hours after thoracentesis and no change in the remaining patient. The overall increase was significant. There were no concomitant changes in $\mathrm{PA}_{\mathrm{A}} \mathrm{ao}$ or shunt breathing $100 \%$ oxygen. On this basis they concluded that no modifications in gas exchange occur during the first hours after thoracentesis.

We cannot explain the discrepancy between our results and those of the above mentioned authors. The varied underlying diseases of our patients are similar to those of the patients in the other studies and even among patients with effusions of similar cause (such as tuberculosis and transudates due to congestive heart failure) discrepancies still exist. Another important factor varying between different series might be differences in the duration of the effusions at the time of drainage, since it has been reported that there may be increased interstitial capillary permeability ${ }^{3}$ or an alteration of surfactant synthesis in the compressed lung' that increases with time. We were not able to determine with certainty the duration of effusions in many cases, but the fact that the underlying pathological conditions in our patients were similar to those in other series suggests that differences in duration are unlikely to be important. Moreover, the amount of fluid aspirated in our patients was similar to that removed in these other studies. The variability of the results might be due to differences in the way aspiration was performed. In our series, as we pointed out above, we took care to ensure uniform slow withdrawal of the fluid.

The relief of dyspnoea experienced by the patients after drainage cannot be explained completely by the improved oxygenation of the blood, which was generally modest. It has, moreover, been observed in all reported series regardless of changes of arterial $\mathrm{Po}_{2}$. The mechanism or mechanisms of this subjective improvement remain uncertain. An increase in lung volumes is a constant finding, but may take days or even weeks to develop to a significant degree. ${ }^{1} 689$ Immediate changes are usually very modest and highly variable. ${ }^{26}$ Furthermore, no significant changes in expiratory flow rate have been observed. ${ }^{2}$ The relief of dyspnoea therefore cannot be adequately explained by changes either in lung volumes or in the mechanics of breathing, but it may be the result of decreased stimulation of lung or chest wall mechanoreceptors or both.

\section{References}

${ }^{1}$ Karetzky MS, Kothary GA, Fourre JA, Khan AU. Effect of thoracentesis on arterial oxygen tension. Respiration 1978;36:96-103.

${ }^{2}$ Brown NE, Zamel N, Aberman A. Changes in pulmonary mechanics and gas exchange following thoracentesis. Chest 1978;74:540-2.

${ }^{3}$ Brandstetter RD, Cohen RP. Hypoxemia after thoracentesis. JAMA 1979;242:1060-1.

${ }^{4}$ Robin ED, Carroll CE, Zelis R. Pulmonary edema. $N$ Engl J Med 1973;288:239-46, 292-304.

${ }^{5}$ Light RW, McGregor MI, Luchsinger PG, Ball WG. Pleural effusions: the diagnostic separation of transudates and exudates. Ann Intern Med 1972;77:507-13.

${ }^{6}$ Light RW, Stansbury DW, Brown SE. Changes in pulmonary function following therapeutic thoracentesis. Chest 1981;80:375 (abstract).

${ }^{7}$ Trapnell DH, Thurston JGB. Unilateral pulmonary oedema after pleural aspiration. Lancet 1970;i:1367-9.

${ }^{8}$ Altschule MD, Zamcheck $\mathbf{N}$. The effects of pleural effusion on respiration and circulation in man. J Clin Invest 1944;23:325-31.

${ }^{9}$ Yoo OH, Ting EY. The effect of pleural effusion on pulmonary function. Am Rev Respir Dis 1964;89:5563. 